\title{
Range-wide phenotypic and genetic differentiation in wild sunflower
}

Edward V. McAssey ${ }^{1,2}$, Jonathan Corbi ${ }^{1,3}$ and John M. Burke ${ }^{1 *}$

\begin{abstract}
Background: Divergent phenotypes and genotypes are key signals for identifying the targets of natural selection in locally adapted populations. Here, we used a combination of common garden phenotyping for a variety of growth, plant architecture, and seed traits, along with single-nucleotide polymorphism (SNP) genotyping to characterize range-wide patterns of diversity in 15 populations of wild sunflower (Helianthus annuus L.) sampled along a latitudinal gradient in central North America. We analyzed geographic patterns of phenotypic diversity, quantified levels of within-population SNP diversity, and also determined the extent of population structure across the range of this species. We then used these data to identify significantly over-differentiated loci as indicators of genomic regions that likely contribute to local adaptation.

Results: Traits including flowering time, plant height, and seed oil composition (i.e., percentage of saturated fatty acids) were significantly correlated with latitude, and thus differentiated northern vs. southern populations. Average pairwise $F_{\text {ST }}$ was found to be 0.21 , and a STRUCTURE analysis identified two significant clusters that largely separated northern and southern individuals. The significant FST outliers included a SNP in HaFT2, a flowering time gene that has been previously shown to co-localize with flowering time QTL, and which exhibits a known cline in gene expression.

Conclusions: Latitudinal differentiation in both phenotypic traits and SNP allele frequencies is observed across wild sunflower populations in central North America. Such differentiation may play an important adaptive role across the range of this species, and could facilitate adaptation to a changing climate.
\end{abstract}

Keywords: Latitudinal variation, Local adaptation, Phenotypic differentiation, Population genetics, Sunflower

\section{Background}

Local adaptation, wherein populations have higher fitness in their 'home' environments than in non-native locales, is a topic of great interest in the field of evolutionary biology (e.g., [1]). The genetic basis of such adaptive divergence has not, however, been elucidated in the vast majority of non-model organisms. For plants, the selective pressures leading to local adaptation can include a variety of abiotic and biotic factors such as: soil type [2-4], water availability [5], photoperiod [6], temperature [7], herbivores [8], mycorrhizal associations [9], and proximity to agricultural fields [10]. Because these selective pressures are expected to produce characteristic patterns of genetic variation in and near genes

\footnotetext{
* Correspondence: jmburke@uga.edu

${ }^{1}$ Department of Plant Biology, University of Georgia, Miller Plant Sciences

Building, Athens, GA 30602, USA

Full list of author information is available at the end of the article
}

conferring adaptive differences, population genetic approaches have the potential to provide insight into the genes, or at least genomic regions, responsible for producing locally adapted traits across the range of a species.

In the case of divergent selection, which would be expected to play an important role in the production of locally adapted populations, the focus is typically on measures of population genetic differentiation. More specifically, divergent selective pressures would be expected to produce elevated population structure in the vicinity of targeted genes relative to the genome-wide average (e.g., [11-14]). In contrast, balancing selection would be expected to result in much lower levels of population genetic differentiation $[15,16]$. When combined with high-throughput genotyping approaches, such population genetic approaches have been used to identify genes thought to be involved in adaptation in a 
variety of species, including boreal black spruce [17], Atlantic cod [18], prairie-chickens [19], and moor frogs [20].

In addition to overall levels of population differentiation, clinal patterns of genetic variation can also be indicative of local adaptation (e.g., [21, 22]). A variety of environmental variables typically vary across the ranges of species, and thus there may be selection for different phenotypic values at the extremes of a species' range. While allele frequencies at many loci might exhibit weak correlations across a given environmental contrast due to the joint effects of genetic drift and gene flow, alleles at loci that play an important role in local adaptation should clearly correlate with relevant environmental variables [21]. For example, adaptive clines in allele frequency have been identified in Arabidopsis thaliana for the flowering time genes FRIGIDA [23] and PHYTOCROME C [24], in Populus tremula for the flowering time gene PHYTOCHROME B2 [25], in Drosophila melanogaster for the insulin-signaling gene INSULIN-LIKE RECEPTOR [26], and in Peromyscus polionotus for the coat color gene AGOUTI [27]. While the above studies have provided tremendous insight into the genetic basis of local adaptation, studies of non-model organisms will help to broaden our understanding of this fundamental evolutionary process. In the present paper, we report on range-wide patterns of phenotypic and genetic diversity in common sunflower, Helianthus annuus.

Sunflower is a member of the Compositae (a.k.a., the Asteraceae), which is one of the largest and most diverse families of flowering plants. The native range of common sunflower spans much of North America, and wild populations occur in habitats that are characterized by variation in a wide range of environmental variables, including: photoperiod, growing season, minimum/maximum temperatures, and precipitation. Common sunflower is also the wild progenitor of cultivated sunflower (also $H$. annuus), which is native to east-central North America [28-30] and is one of the world's most important oilseed crops [31]. Cultivated sunflower shows significant phenotypic differences as compared to common sunflower, including branching, flowering time, plant height, and various seed traits [32].

Here, we describe patterns of phenotypic and genetic diversity within and among 15 wild sunflower populations across a latitudinal gradient in central North America. We grew and phenotyped individuals from these populations in a greenhouse environment and genotyped them using a single-nucleotide polymorphism (SNP) array targeting 384 loci distributed throughout the sunflower genome. We used these data to investigate geographic patterns of phenotypic differentiation, describe overall patterns of population genetic variation, and identify loci that harbor the population genetic signature of local adaptation. We also placed our population genetic results in the context of prior quantitative trait locus (QTL) mapping studies in sunflower to determine whether highly differentiated loci co-localize with known QTL regions.

\section{Methods \\ Plant materials and phenotypic analyses}

Seeds from 15 wild-collected populations of $H$. annuus were obtained from the USDA's North Central Regional Plant Introduction Station (Ames, IA). These populations, which were sampled from a range of latitudes across central North America (Fig. 1; Table 1), were selected to represent truly wild populations that appear to be free from the effects of past introgression with cultivated sunflower (L. Marek and G. Seiler, personal communication). Care was taken to avoid sampling different subspecies of $H$. annuus (e.g., $H$. annuus ssp. Texanus), as that could inflate genetic structure and/or phenotypic differentiation. Prior to germination, all seeds were cleaned with $3 \%$ hydrogen peroxide, rinsed with deionized water, and placed on moist filter paper in a petri dish. To break dormancy, petri dishes were placed at 4 $\mathrm{C}$ in a dark cold room for 14 days. After the cold treatment, they were moved into a growth room where they were maintained under $16 \mathrm{~h}$ days at $23 \mathrm{C}$. Following germination, seedlings were planted in soil trays. Once established, these seedlings were transplanted into soil pots (900 Classic, Nursery Supplies Inc, Kissimmee, FL) and moved to the greenhouse, where supplemental lighting provided a consistent cycle of $16 \mathrm{~h}$ days and $8 \mathrm{~h}$ nights.

Plants were arranged in the greenhouse in four blocks, each of which contained five individuals from each of the 15 populations (75 individuals total per block). All plants were phenotyped for a variety of traits, including: days to four pairs of true leaves, days to flowering, plant height at senescence, branching architecture, seed size, and seed oil content/composition. Because wild sunflower is self-incompatible, manual crosses were performed to produce seeds. This involved intercrossing individuals within populations (i.e., bulked pollen collected from individuals within a population was used to pollinate individuals within that population), with inflorescences being bagged to prevent cross-contamination. Seeds were then collected at physiological maturity and phenotyped. Oil traits were assessed following established protocols [32]. Briefly, percent oil content was determined via pulsed nuclear magnetic resonance (NMR) analyses using a Bruker MQ20 Minispec NMR analyzer (Billerica, MA) that had been calibrated with known standards. Fatty acid composition was determined by gas chromatography (Hewlett-Packard, Palo Alto, CA) with 


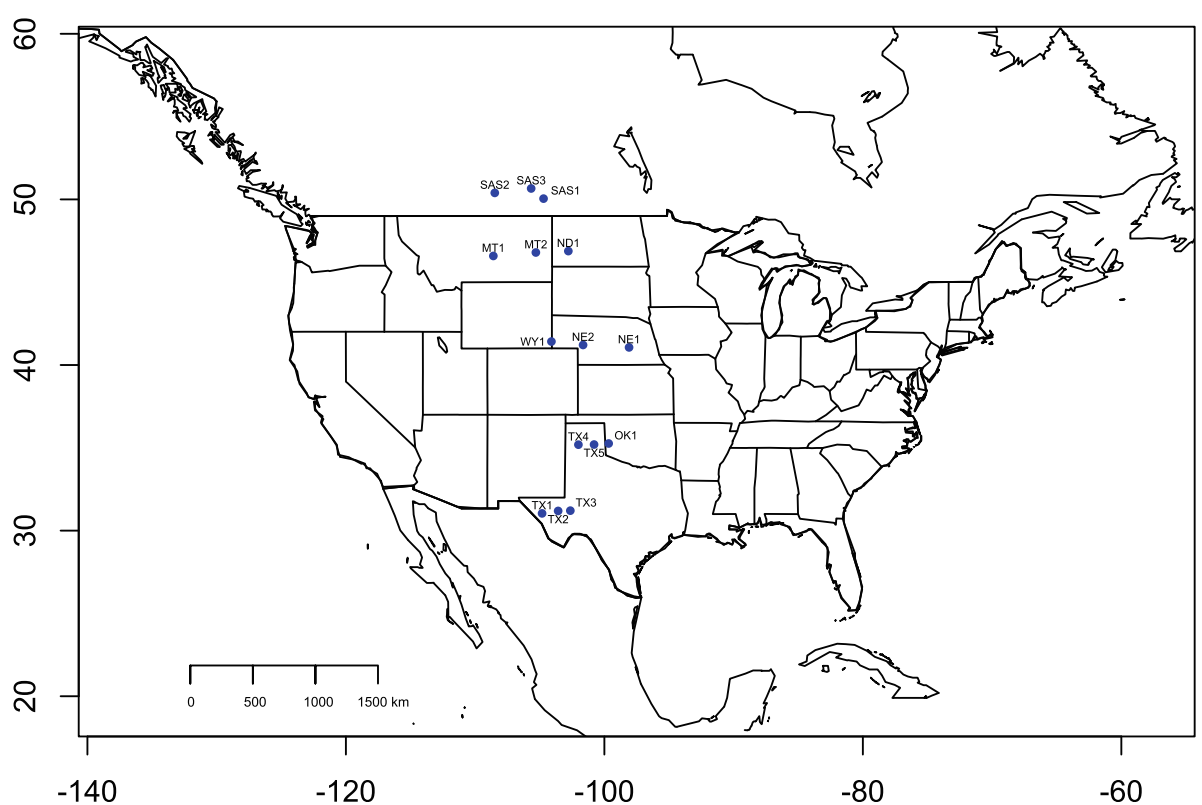

Fig. 1 Map of the locations of the 15 populations used in this study in the central USA and Canada. Map was constructed in R using the library 'maps' [65]

known fatty acid standards (Nu-Check Prep, Elysian, $\mathrm{MN})$.

All traits were tested for deviations from normality by determining whether a frequency histogram of trait values across all 286 full grown individuals (14 of the originally planted individuals died early in development, but at least 12 individuals for each population were analyzed (Table 1)) was significantly different from a normal distribution with the Shapiro-Wilk test in JMP 11 (SAS Institute, Cary, NC) and trait values were transformed using a Box-Cox transformation [33] as necessary. Restricted maximum likelihood was used with region as a fixed effect (blocks and a block-by-region interaction were included as random effects) to test for regional differences in trait values. For fatty acid traits, the date of fatty acid extraction was used as a blocking factor instead of greenhouse block because an inspection of the raw data indicated clear variation in extraction efficiency across days. Least-squares means were compared amongst regions using Tukey's test.

Table 1 Range-wide population sampling information

\begin{tabular}{|c|c|c|c|c|c|c|}
\hline Population & State/Province & Country & USDA PI & Sample Size & Latitude & Longitude \\
\hline TX1 & Texas & USA & 413160 & 20 & 31.041 & -104.821 \\
\hline TX2 & Texas & USA & 664692 & 20 & 31.189 & -103.578 \\
\hline TX3 & Texas & USA & 468476 & 20 & 31.206 & -102.635 \\
\hline TX4 & Texas & USA & 468477 & 20 & 35.190 & -102.010 \\
\hline TX5 & Texas & USA & 468482 & 20 & 35.199 & -100.799 \\
\hline OK1 & Oklahoma & USA & 468486 & 12 & 35.262 & -99.669 \\
\hline NE1 & Nebraska & USA & 586870 & 20 & 41.063 & -98.091 \\
\hline NE2 & Nebraska & USA & 659440 & 20 & 41.211 & -101.649 \\
\hline WY1 & Wyoming & USA & 649806 & 20 & 41.418 & -104.098 \\
\hline MT1 & Montana & USA & 531035 & 20 & 46.585 & -108.592 \\
\hline MT2 & Montana & USA & 586817 & 20 & 46.795 & -105.302 \\
\hline ND1 & North Dakota & USA & 613750 & 20 & 46.879 & -102.789 \\
\hline SAS1 & Saskatchewan & Canada & 592320 & 19 & 50.048 & -104.707 \\
\hline SAS2 & Saskatchewan & Canada & 592311 & 15 & 50.394 & -108.480 \\
\hline SAS3 & Saskatchewan & Canada & 592316 & 20 & 50.660 & -105.665 \\
\hline
\end{tabular}




\section{DNA extractions and SNP genotyping}

Leaf tissue was harvested from the 286 fully grown (Table 1) individuals described above and DNA was extracted using the Qiagen DNeasy Plant Mini Kit (Valencia, CA). All DNA samples were quantified using a NanoDrop (Thermo Scientific, Wilmington, DE) and diluted to $50 \mathrm{ng} / \mu \mathrm{l}$ prior to genotyping. Each sample was then genotyped using a GoldenGate assay (Illumina, San Diego, CA) targeting 384 SNPs selected from the larger collection of sunflower SNPs described by Bachlava et al., [34]. These loci were chosen to provide even coverage of the 17 sunflower linkage groups (LGs), with an average of one SNP every $3.5 \mathrm{cM}$. Genotype calls were made using Illumina's GenomeStudio (ver. 2011.1) followed by manual inspection. Loci that exhibited aberrant hybridization signals (perhaps due to presence/absence variation or the occurrence of duplicate genes), an overall lack of polymorphism (i.e., minor allele frequency $<0.05$ ), and/or large amounts of missing data (i.e., fraction of missing data $>0.05$ ) were removed prior to population genetic analysis. A total of 246 loci (average $=14.5$ per LG; range $=11-20$ per LG) were retained for further analysis (http://dx.doi.org/10.5061/dryad.6p1c4).

\section{Population genetic analyses}

Measures of genetic diversity, including the percentage of polymorphic loci, observed heterozygosity $\left(\mathrm{H}_{\mathrm{o}}\right)$, and Nei's unbiased expected heterozygosity $\left(\mathrm{UH}_{\mathrm{e}}\right.$; [35]) were calculated at the population level using GenAlEx (version 6.501; [36]). We also used GenAlEx to investigate genetic differentiation amongst populations by performing an analysis of molecular variance (AMOVA) with 999 permutations to determine the level of population structure in our dataset. Finally, the program STRUCTURE (version 2.3.4) [37] was used to investigate population genetic structure across the species range. Specifically, STRUCTURE was run using the admixture model from $K=1$ to 17 population genetic clusters with a burn-in of 100,000 and 1,000,000 MCMC iterations (with 20 replicates for each $K$ value). Results were imported into STRUCTURE Harvester [38] where the most likely value of $K$ was determined using the DeltaK method [39]. STRUCTURE, was additionally used to test individual subsets of the data to investigate finer levels of genetic structure.

The potential role of local selective pressures in shaping diversity at individual loci was investigated using multiple approaches. First, we used Arlequin to calculate 20,000 simulations in order to obtain a null distribution for $\mathrm{F}_{\mathrm{ST}}$, which was then used to develop a $99 \%$ confidence interval for high and low outlier identification (version 3.5.1.2; [13]). In general terms, overdifferentiated loci are regarded as candidates for local adaptation, while under-differentiated loci are generally viewed as candidates for balancing selection [15, 16], or possibly a sweep across multiple populations [40]. BayeScan was also used to test for selection by comparing the posterior probabilities of two models (selection vs. no selection) for each locus [14]. Following Foll and Gaggiotti (version 2.1; [14]), loci whose posterior probability for the model including selection was greater than 0.91 were regarded as being 'strong' $\mathrm{F}_{\mathrm{ST}}$ outlier candidates. We then mined the sunflower QTL literature to identify any QTL whose confidence interval co-localized with a putative local adaptation SNP identified in this study, as such overlapping loci might be particularly attractive candidate regions for future research. Colocalization information was obtained using previously published studies from a variety of sunflower crosses $[32,41-44]$.

\section{Results}

\section{Phenotypic diversity}

We identified numerous traits that exhibited differentiation amongst the five sampled regions, with latitude being a significant factor in the partitioning of phenotypic diversity for traits such as flowering time, plant height, branching, and a number of seed oil traits (Table 2; Additional file 1). Individuals from the southern regions (Texas and Oklahoma, Regions 1 and 2; Table 2; Additional file 1) tended to flower later, grow taller, have thicker stems, and have a higher proportion of saturated fatty acids within their seeds compared to individuals from the northern regions found in Saskatchewan, North Dakota and Montana (Regions 4 and 5; Table 2; Additional file 1). The fatty acid composition data also showed some interesting trends, with the saturated type (i.e., palmitic and stearic acid) showing the same sort of regional differentiation as noted above. In contrast, the unsaturated types (i.e., oleic acid and linoleic acid) did not show significant differences between regions. Seed oil content showed no significant differences among regions across the entire range (Table 2; Additional file 1). Aside from the aforementioned differentiation in saturated fatty acid percentage in seed oils, regions were significantly differentiated for seed length with respect to latitude. While seed weight and seed width both exhibit some regional differences, the differences were not due to latitude as the most southern region was not significantly different from the most northern region for these two traits (Table 2; Additional file 1). Notably, the latitudinal trends found in saturated fatty acid content and flowering time are consistent with the results of previous studies $[45,46]$. While total branching exhibited significant differences among regions, there was no clear trend with respect to latitude. However, plants from Texas and Oklahoma (Regions 1 and 2; Table 2; Additional file 1) had significantly more top branching compared to the three northern regions. Other plant architecture traits, such as branch length and the extent of secondary, tertiary, or 
Table 2 Phenotypic variability among five latitudinal regional groupings of sunflower populations

\begin{tabular}{|c|c|c|c|c|c|c|c|}
\hline Trait & F-ratio & P-value & $\begin{array}{l}\text { Region 1: TX1, } \\
\text { TX2, TX3 }\end{array}$ & $\begin{array}{l}\text { Region 2: TX4, } \\
\text { TX5, OK1 }\end{array}$ & $\begin{array}{l}\text { Region 3: NE1, } \\
\text { NE2, WY1 }\end{array}$ & $\begin{array}{l}\text { Region 4: MT1, } \\
\text { MT2, ND1 }\end{array}$ & $\begin{array}{l}\text { Region5: SAS1 } \\
\text { SAS2, SAS3 }\end{array}$ \\
\hline Days to Four Pairs of Leaves & 4.1906 & 0.0267 & $23.42^{\mathrm{B}}$ & $23.85^{\mathrm{A}, \mathrm{B}}$ & $24.17^{A, B}$ & $24.28^{\mathrm{A}, \mathrm{B}}$ & $24.98^{\mathrm{A}}$ \\
\hline Days to Flowering & 226.6019 & $<.0001$ & $69.93^{\mathrm{B}}$ & $75.80^{\mathrm{A}}$ & $68.77^{\mathrm{B}}$ & $51.75^{C}$ & $49.31^{C}$ \\
\hline $\begin{array}{l}\text { Days between Four Pairs of } \\
\text { Leaves and Flowering }\end{array}$ & 74.905 & $<.0001$ & $46.52^{A, B}$ & $51.98^{\mathrm{A}}$ & $44.53^{B}$ & $27.47^{C}$ & $30.44^{c}$ \\
\hline Plant Height (cm) & 89.4095 & $<.0001$ & $191.55^{\mathrm{A}}$ & $170.32^{A, B}$ & $164.19^{B}$ & $110.85^{C}$ & $78.17^{D}$ \\
\hline Longest Branch Length (cm) & 15.667 & 0.0002 & $57.72^{\mathrm{A}}$ & $41.66^{\mathrm{B}}$ & $47.83^{B}$ & $57.86^{\mathrm{A}}$ & $45.68^{B}$ \\
\hline Degree of Branching ${ }^{1}$ & 18.3082 & $<.0001$ & $3.02^{\mathrm{A}}$ & $2.46^{\mathrm{B}}$ & $2.62^{\mathrm{B}}$ & $3.30^{\mathrm{A}}$ & $2.64^{B}$ \\
\hline Stem Diameter (mm) & 17.9575 & $<.0001$ & $15.13^{\mathrm{A}}$ & $13.82^{\mathrm{A}, \mathrm{B}}$ & $12.98^{\mathrm{B}}$ & $13.19^{\mathrm{B}}$ & $10.46^{C}$ \\
\hline Total Branching & 9.0473 & 0.0012 & $10.20^{A, B}$ & $8.58^{B, C}$ & $7.31^{c}$ & $10.97^{\mathrm{A}}$ & $9.87^{A, B}$ \\
\hline Top Half Branching & 35.1134 & $<.0001$ & $7.52^{\mathrm{A}}$ & $7.21^{\mathrm{A}}$ & $5.17^{B}$ & $4.02^{B, C}$ & $3.43^{C}$ \\
\hline Weight per Seed & 14.0714 & 0.0003 & $0.007^{B, C}$ & $0.006^{C}$ & $0.008^{\mathrm{A}, \mathrm{B}}$ & $0.009^{A}$ & $0.008^{\mathrm{A}, \mathrm{B}}$ \\
\hline Seed Length (mm) & 31.0011 & 0.0005 & $4.81^{B, C}$ & $4.64^{c}$ & $4.92^{\mathrm{B}}$ & $5.14^{\mathrm{A}}$ & $5.27^{\mathrm{A}}$ \\
\hline Seed Width (mm) & 6.1076 & 0.009 & $2.40^{A, B}$ & $2.28^{\mathrm{B}}$ & $2.41^{\mathrm{A}, \mathrm{B}}$ & $2.55^{\mathrm{A}}$ & $2.45^{A, B}$ \\
\hline Percent Palmitic Acid & 31.6781 & 0.0003 & $5.05^{\mathrm{A}}$ & $4.60^{A, B}$ & $4.09^{\mathrm{B}}$ & $3.93^{\mathrm{B}}$ & $3.09^{c}$ \\
\hline Percent Stearic Acid & 13.7987 & 0.014 & $2.26^{\mathrm{A}}$ & $2.34^{\mathrm{A}, \mathrm{B}}$ & $1.56^{\mathrm{A}, \mathrm{B}, \mathrm{C}}$ & $1.23^{B, C}$ & $0.82^{C}$ \\
\hline Percent Linoleic Acid & 0.6313 & 0.6587 & $60.01^{\mathrm{A}}$ & $52.39^{\mathrm{A}}$ & $57.94^{\mathrm{A}}$ & $63.45^{\mathrm{A}}$ & $59.06^{\mathrm{A}}$ \\
\hline Percent Oleic Acid & 0.6725 & 0.6353 & $32.69^{A}$ & $40.69^{A}$ & $36.33^{\mathrm{A}}$ & $31.39^{A}$ & $37.01^{\mathrm{A}}$ \\
\hline Percent Saturated Fatty Acids & 60.4987 & 0.0043 & $7.30^{\mathrm{A}}$ & $6.93^{A, B}$ & $5.66^{\mathrm{B}, \mathrm{C}}$ & $5.15^{C}$ & $3.90^{\mathrm{D}}$ \\
\hline Percent Oil & 1.059 & 0.4418 & $23.48^{\mathrm{A}}$ & $21.09^{\mathrm{A}}$ & $22.98^{\mathrm{A}}$ & $22.84^{\mathrm{A}}$ & $23.05^{\mathrm{A}}$ \\
\hline
\end{tabular}

'Degree of branching describes the greatest amount of branching attained (i.e., a value of 2 corresponds to secondary, 3 corresponds to tertiary) Values that share a superscript letter are not statistically different

higher-order branching, were significantly different between regions, but those differences likewise did not show a latitudinal pattern (Table 2; Additional file 1). Interestingly, no traits exhibited significant differentiation between all five regions (Table 2; Additional file 1).

\section{Population genetic structure}

Calculation of population genetic statistics for each of the 15 populations revealed a substantial, albeit variable, amount of genetic diversity across the range of wild sunflower (Table 3). There was no trend towards either latitudinal extreme of the range having a reduced level of genetic diversity (Table 3). However, two populations (WY1 and ND1) exhibited a noticeably lower percentage of polymorphic loci compared to the other 13 populations. An analysis of molecular variance revealed that approximately $20 \%$ of the observed genetic variation could be attributed to population level differentiation (data not shown). Of the remaining genetic variation, $76 \%$ was seen at the within individual levels whereas only $4 \%$ was found at the amongindividual level. A STRUCTURE [37] analysis of the data coupled with the DeltaK method for determining the most likely number of population genetic clusters [39] identified $K=2$ clusters (Fig. 2). The STRUCTURE bar plot for $K=2$ revealed a north-south divide with the east-central portion of Region 3 corresponding to a transition zone (Fig. 2). An additional STRUCTURE run containing only the southernmost six populations also indicated that $K=2$. For this level of $K$, TX1 was separated from the remaining five populations found in Texas and Oklahoma, although $K=6$ showed a secondary peak (Additional files 2, 3, and 4). When the northernmost six populations were analyzed by STRUCTURE, $K=2$ was again the most well-supported number of genetic groups. Similar to the result for the southern portion of the range, only a single population (ND1) in the northern portion of the range was separated from the other five populations at $K=2$ (Additional files 5 and 6). Additionally, since the initial full dataset STRUCTURE analysis suggested that two of the three middle latitude populations were more southern while the other population appeared more northern we performed more STRUCTURE analyses to explore differentiation within the middle of the range. To study the middle latitude populations we added NE1 and NE2 to the southern dataset, and WY1 to the northern dataset for further testing. When we performed STRUCTURE analyses of these larger groupings, we found that $K=3$ for the northern cluster. The three clusters corresponded to ND1, WY1, and the remaining populations. Additionally, we found that $K$ $=2$ for the southern cluster with the one cluster corresponding to NE2 individuals, and the other contained the remaining seven populations. 
Table 3 Mean and standard error (SE) of population genetic statistics for 15 wild sunflower populations

\begin{tabular}{|c|c|c|c|c|c|c|c|c|}
\hline Population & USDA PI & & $\mathrm{Na}^{\mathrm{a}}$ & $\mathrm{Ne}^{\mathrm{b}}$ & $\mathrm{Ho}^{\mathrm{c}}$ & $\mathrm{uHe}^{\mathrm{d}}$ & $F_{I S}^{e}$ & $P^{f}$ \\
\hline \multirow[t]{2}{*}{ TX1 } & 413160 & Mean & 1.85 & 1.41 & 0.26 & 0.25 & -0.03 & 0.85 \\
\hline & & SE & 0.02 & 0.02 & 0.01 & 0.01 & 0.02 & \\
\hline \multirow[t]{2}{*}{ TX2 } & 664692 & Mean & 1.80 & 1.46 & 0.26 & 0.28 & 0.04 & 0.80 \\
\hline & & SE & 0.03 & 0.02 & 0.01 & 0.01 & 0.02 & \\
\hline \multirow[t]{2}{*}{ TX3 } & 468476 & Mean & 1.84 & 1.49 & 0.28 & 0.30 & 0.05 & 0.84 \\
\hline & & SE & 0.02 & 0.02 & 0.01 & 0.01 & 0.02 & \\
\hline \multirow[t]{2}{*}{ TX4 } & 468477 & Mean & 1.86 & 1.49 & 0.28 & 0.30 & 0.03 & 0.86 \\
\hline & & SE & 0.02 & 0.02 & 0.01 & 0.01 & 0.02 & \\
\hline \multirow[t]{2}{*}{ TX5 } & 468482 & Mean & 1.91 & 1.49 & 0.26 & 0.30 & 0.10 & 0.91 \\
\hline & & SE & 0.02 & 0.02 & 0.01 & 0.01 & 0.02 & \\
\hline \multirow[t]{2}{*}{ OK1 } & 468486 & Mean & 1.80 & 1.46 & 0.26 & 0.28 & 0.05 & 0.80 \\
\hline & & SE & 0.03 & 0.02 & 0.01 & 0.01 & 0.02 & \\
\hline \multirow[t]{2}{*}{ NE1 } & 586870 & Mean & 1.91 & 1.51 & 0.30 & 0.31 & 0.00 & 0.91 \\
\hline & & SE & 0.02 & 0.02 & 0.01 & 0.01 & 0.02 & \\
\hline \multirow[t]{2}{*}{ NE2 } & 659440 & Mean & 1.69 & 1.42 & 0.24 & 0.25 & 0.03 & 0.69 \\
\hline & & SE & 0.03 & 0.02 & 0.01 & 0.01 & 0.02 & \\
\hline \multirow[t]{2}{*}{ WY1 } & 649806 & Mean & 1.57 & 1.36 & 0.22 & 0.21 & -0.05 & 0.57 \\
\hline & & SE & 0.03 & 0.03 & 0.02 & 0.01 & 0.02 & \\
\hline \multirow[t]{2}{*}{ MT1 } & 531035 & Mean & 1.89 & 1.46 & 0.30 & 0.28 & -0.08 & 0.89 \\
\hline & & SE & 0.02 & 0.02 & 0.01 & 0.01 & 0.02 & \\
\hline \multirow[t]{2}{*}{ MT2 } & 586817 & Mean & 1.86 & 1.48 & 0.28 & 0.29 & -0.01 & 0.86 \\
\hline & & SE & 0.02 & 0.02 & 0.01 & 0.01 & 0.02 & \\
\hline \multirow[t]{2}{*}{ ND1 } & 613750 & Mean & 1.59 & 1.36 & 0.24 & 0.22 & -0.12 & 0.59 \\
\hline & & SE & 0.03 & 0.02 & 0.02 & 0.01 & 0.02 & \\
\hline \multirow[t]{2}{*}{ SAS1 } & 592320 & Mean & 1.89 & 1.50 & 0.27 & 0.30 & 0.08 & 0.89 \\
\hline & & SE & 0.02 & 0.02 & 0.01 & 0.01 & 0.02 & \\
\hline \multirow[t]{2}{*}{ SAS2 } & 592311 & Mean & 1.82 & 1.47 & 0.28 & 0.29 & 0.02 & 0.82 \\
\hline & & SE & 0.02 & 0.02 & 0.01 & 0.01 & 0.02 & \\
\hline \multirow[t]{2}{*}{ SAS3 } & 592316 & Mean & 1.85 & 1.48 & 0.27 & 0.29 & 0.04 & 0.85 \\
\hline & & SE & 0.02 & 0.02 & 0.01 & 0.01 & 0.02 & \\
\hline
\end{tabular}

${ }^{a}$ Number of alleles per locus

${ }^{b}$ Effective number of alleles per locus

c Observed heterozygosity

d Unbiased expected heterozygosity

e Inbreeding coefficient

${ }^{f}$ Percent polymorphic loci

\section{Outlier identification}

Multiple outlier identification programs highlighted the existence of an overlapping set of loci that exhibit the signature of local adaptation (Table 4). Arlequin identified eight loci that were highly differentiated in a global $\mathrm{F}_{\mathrm{ST}}$ calculation (all possible pairwise $\mathrm{F}_{\mathrm{ST}}$ combinations; 99 \% confidence intervals). These loci included: one SNP on LG4 with no annotation; two SNPs located near the distal end of LG 6, one in HaFT2 [46, 47] and the other in a gene with homology to a mitogen-activated protein kinase kinase kinase 14; one SNP on LG7 in a gene with high similarity to a gene in the armadillo repeat family of proteins in A. thaliana; one SNP on LG10 in the GRAS/DELLA transcription factor GAI; two SNPs on LG 12, one corresponding to an EF-hand-like domaincontaining gene, and the other corresponding to a protein of unknown function; and one SNP located on LG 14 in a gene with high similarity to Defective Cuticle Ridges (DCR) in A. thaliana. BayeScan provided complementary outlier results by identifying three highly differentiated loci (SNPs within the DCR homolog, the GRAS/DELLA transcription factor, and the gene containing the EF-hand-like domain) already highlighted by Arlequin. Four loci had evidence of being significantly under-differentiated from both Arlequin and BayeScan. There were two under-differentiated loci on LG 13, including one SNP in a gene with an alpha-beta plait nucleotide binding role and another SNP in a gene with homology to $5^{\prime}$-AMP-activated protein kinase. SNPs in a glycoside hydrolase and a guanylate binding gene also had exceptionally low $\mathrm{F}_{\mathrm{ST}}$, and were found on LGs 8 and 17 , respectively (data not shown).

\section{Co-localization of SNP outliers with known QTL}

The locations of our eight over-differentiated loci were compared to the locations of previously mapped sunflower QTL to identify traits potentially involved in local adaptation. On LG 4, an unannotated gene co-localized with a QTL for leaf number [44]. As noted above the distal end of LG 6 contains two $\mathrm{F}_{\mathrm{ST}}$ outliers: HaFT2 and a gene with a putative kinase function. Both of these colocalize with QTL related to flowering time in two sunflower mapping populations, ANN1238 $\times$ CMS 89 [32] and ANN1238 $\times$ Hopi [42]. This genomic region is actually known to contain multiple $H a F T$ paralogs, including HaFT1, which has been shown to be important with respect to cultivated sunflower's photoperiod response [46, 47]. In addition to co-localization with the flowering time QTL in this region, there are QTL for morphological traits (e.g., achene width, plant height, and number of ray flowers) and even a QTL for leaf fungal damage. The SNP outlier on LG 7, from an EST with homology to an ARM repeat protein, co-localizes with QTL for flowering time, plant height, leaf number, and head herbivory, as well $[32,44]$. Interestingly, two loci with strong support from both Arlequin and BayeScan (the GRAS/DELLA transcription factor and the $D C R$ homolog, which map to LGs 10 and 14, respectively), did not co-localize with any known QTL. One of the two outliers on LG12, an unannotated gene, co-localized with leaf shape and number of heads [32]. Finally, the EF-handdomain containing gene co-localized with a QTL for head total (one way of describing the degree of branching), as well as leaf and branch traits, found on LG 12 (Table 4). 


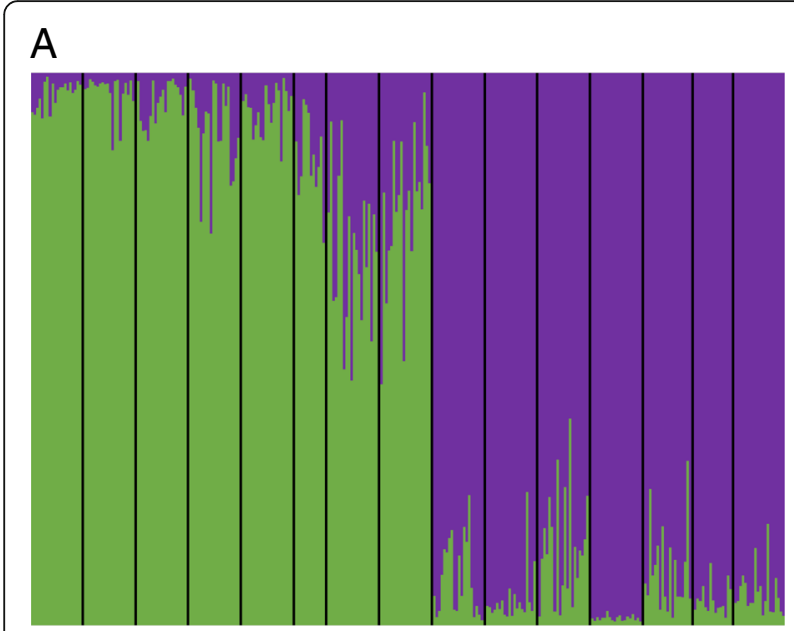

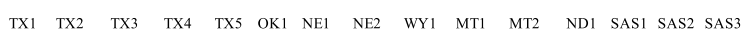

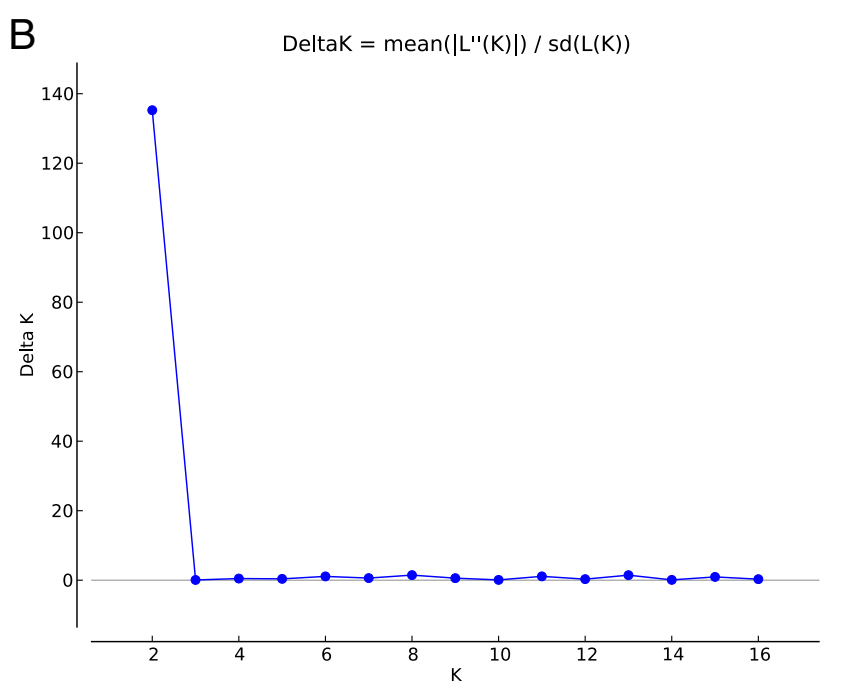

Fig. 2 Population genetic structure of wild sunflower individuals. a STRUCTURE bar plot of full dataset. Populations correspond to those in Table 1. b DeltaK plotted across all values of $K$ tested. Figure constructed in STRUCTURE HARVESTER [38]

Under-differentiated loci co-localized with QTL for a variety of different traits. Of particular interest were two low $\mathrm{F}_{\mathrm{ST}}$ outliers located near each other on LG 13 that colocalized with a shared set of QTL that included: number of branches, number of heads, head and leaf herbivory, stem diameter, achene length, leaf area, and stem height $[32,42-44]$.

\section{Discussion}

Populations across the range of wild sunflower harbor an exceptional amount of phenotypic diversity. The extent to which those traits contribute to local adaptation is an important question that can be addressed in a number of ways including reciprocal transplants, common garden measurements, and population genome scans. In our analyses, many traits (e.g., flowering time, plant height, plant architecture, and seed oil composition) were differentiated in conjunction with latitude. As sunflower is a seed oil crop, there has been a considerable of research done to describe and uncover the genetic mechanism behind seed oil variation. In breeding lines, strong artificial selection has created divergent germplasm groups with vastly different oil profiles. In the wild, natural selection may act as a strong force in affecting what relative amounts of saturated and unsaturated fatty acids are most beneficial for populations living in certain environments.

\section{Common garden phenotypic variation}

Seed oil composition exhibited significant latitudinal differentiation across the range. Previous studies of seed oil composition in a variety of species have revealed a

Table 4 Summary of candidate genes involved in local adaptation. FST values were determined by Arlequin and/or BayeScan and were cross-referenced against QTL information to determine the extent of QTL co-localization

\begin{tabular}{lllllll}
\hline Gene name & $F_{S T}$ & LG & CM Position & Arlequin $^{\text {a }}$ & Bayescan ${ }^{\text {a }}$ & QTL $^{\text {b }}$ \\
\hline Mitogen activated protein kinase kinase kinase 14 & 0.38 & 6 & 53.72 & $2 / 5$ & $0 / 5$ & A, B, C, D, E, F, G, H, N, O, X, Y, Z, AA \\
DCR & 0.38 & 14 & 67.27 & $2 / 5$ & $5 / 5$ & None \\
No annotated hit heliagene or NCBI & 0.40 & 12 & 65.62 & $1 / 5$ & $0 / 5$ & I, L, Y \\
HaFT2 & 0.47 & 6 & 65.9 & $2 / 5$ & $0 / 5$ & E, F, H, M, N, O, T, U, V, W \\
Armadillo (ARM) repeat & 0.36 & 7 & 19.29 & $1 / 5$ & $0 / 5$ & D, E, J, L, P \\
No annotated hit heliagene or NCBI & 0.37 & 4 & 73.86 & $1 / 5$ & $0 / 5$ & J \\
GRAS/DELLA transcription factor & 0.41 & 10 & 66.87 & $5 / 5$ & $5 / 5$ & None \\
EF-hand-like domain & 0.44 & 12 & 44.1 & $5 / 5$ & $5 / 5$ & J, K, I, Q, R, S, Y
\end{tabular}

${ }^{a}$ Fraction represents the number of times a particular locus was detected as an $\mathrm{F}_{\mathrm{ST}}$ outlier

b Letters represent co-localizing QTL. Key: A - Leaf shape [43], B - Number of ray flowers [32], C - Disc diameter [42], D - Height [32], E - Days to flower [32], F Leaf fungal damage [44], G - Achene width [32], H - Days to flower [42], I - Leaf shape [32], J - Leaf number [44], K - Head total [44], L - Number of heads [32], M - Seed total [44], N - Leaf herbivory [44], O - Head clipping weevil [44], P - Head herbivory [44], Q - Branch number [44], R - Stem diameter [44], S - Leaf shape [44], T - Days to flower [43], U - Height [43], V - Leaf number [43], W - Leaf moisture content [43], X - Height [42], Y - Heads per branch [32], Z - Stem diameter [32], AA - Achene weight [32] 
negative correlation between saturated fatty acid content and latitude and degree of saturation at a relatively coarse geographic scale [45]. By quantifying the percentage of saturated fatty acids across the range of sunflower, we were able to identify a similar trend (Table 2; Additional file 1), albeit at a finer geographic scale. Given that these plants were grown in a common garden, we can infer that the observed differences have a genetic basis, and that functional polymorphisms in the oil biosynthetic pathway exist across the range of wild sunflower. The percentage of saturated fatty acids in seed oils is of considerable evolutionary importance with respect to germination under different environmental conditions. Saturated fatty acids are known to store more usable energy per carbon as compared to unsaturated fatty acids [45], but saturated fatty acids also have higher melting points than unsaturated fatty acids; the associated energy is thus less accessible in cooler temperatures. The resulting inference is that the production of unsaturated fatty acids in higher latitudes is advantageous because it ensures energy availability at lower temperatures [45]. Conversely, saturated fatty acids are better in lower latitudes because they are more energy rich while still being available to germinating seeds due to the comparably warmers temperatures.

Observed differences in flowering time can be interpreted in a similar framework. Growing seasons tend to be shorter in higher latitudes; thus, there is a premium on flowering early to allow seed set before the end of the growing season. Alternatively, in lower latitudes, there is typically a longer growing season that may select for later flowering plants that may grow to a larger size and produce more and/or higher quality seeds. It must, however, be noted that plant height and flowering time are developmentally correlated; as such, they form a suite of inter-related traits $[48,49]$. The differentiation seen in this study confirms some of the patterns of diversity documented by Blackman et al., [46], with northern populations flowering significantly earlier compared to southern populations when grown at $16 \mathrm{~h}$ days. While common garden approaches do isolate the effects of genotype on trait variation, it should be noted that approaches like this do preclude the study of genotype-byenvironment $(\mathrm{G} \times \mathrm{E})$ interactions. Reciprocal transplants across the range would thus be useful to further characterize the relevance of the aforementioned traits in local adaptation. While not the focus of this study, it should be noted that altitude is also a possible cause of differentiation in a suite of traits, as shown by Kooyers et al., [50].

\section{Population genetic structure}

The STRUCTURE analysis of the full dataset revealed an overall north/south division in the natural range of wild sunflower, with a transitional zone occurring in the vicinity Nebraska and Wyoming. Previous sampling of $H$. annuus genetic diversity had hinted at a similar north/south division [51], and our analysis builds on this finding by increasing the marker density and sampling density within each population. Historically, this latitudinal transect has seen similar patterns of genetic differentiation. For example, using transplant gardens, McMillian [52] showed that multiple grassland species exhibited heritable differences in flowering time in which northern populations flowered significantly earlier. When further STRUCTURE analyses were performed on northern and southern subsets of individuals, it was discovered that hierarchical structure exists in our dataset. In other words, the large north/south split identified in the full dataset may have obscured more subtle patterns that differentiate individual populations.

\section{Candidate adaptive loci}

In terms of population genetic differentiation, we identified interesting possible candidates for conferring local adaptation with respect to flowering time. We found two outlier loci on chromosome 6 with SNPs that colocalize with a gene with putative kinase activity and HaFT2. Both loci co-localize with previously identified QTL for flowering time, [32, 42] in addition to other traits (Table 4). FT2 is a gene whose Arabidopsis homolog has been shown to play a major role in promoting flowering [53]. Moreover, the region of sunflower LG 6 where this gene resides has been previously shown to influence flowering time in domesticated vs. wild sunflower [32, 42, 47]. It should be noted that the mapping parents for these crosses consisted of a wild $\times$ crop and wild $\times$ landrace. The extent of linkage disequilibrium (LD) of this region is currently unknown, although previous work indicates that, on average, LD decays quickly in wild sunflower [54]. Studies of cultivated germplasm suggested that there is variation in LD across the sunflower genome [55]. In addition to mapping information, HaFT2 is an exceptional candidate for local adaptation due to previous gene expression work across the range of wild $H$. annuus [46]. In short days, a cline in gene expression was seen for HaFT2 in which northern individuals exhibited higher expression than southern individuals, consistent with this gene playing a role in adaptive differentiation [46]. Our results add to the observation that HaFT2 exhibits a latitudinal cline in gene expression that is consistent with the effects of selection by providing population genetic evidence of selection on this gene, as well.

We uncovered SNPs with significantly elevated population differentiation values on other chromosomes. A strongly differentiated SNP on LG 14 resides in the sunflower homolog of Defective in Cuticle Ridges (DCR). In A. 
thaliana, mutants of $D C R$ have altered trichome development during leaf growth [56, 57]. Trichomes serve a multitude of functions in plants including: reflectance of sunlight to prevent damage [58], retention of water [59], and defense [60]. As many of the aforementioned factors may correlate with growing season, it is difficult to draw any conclusions without additional data. We cannot conclude, for example, that the variants documented herein are in any way causal in nature. Rather, they provide us with a preliminary pool of candidate adaptive regions for further study. Furthermore, since we lack knowledge concerning the strength of linkage disequilibrium in these genomic regions, these SNPs may simply be linked to causal polymorphisms found in nearby genes.

These $\mathrm{F}_{\mathrm{ST}}$ outliers form a list of possible candidate genes for future experiments. Importantly, the extent of linkage disequilibrium needs to be assessed in these genomic regions in order to determine the size of the region of elevated population structure. A possible explanation for the absence of co-localizing QTL for some SNPs is that no wild $\times$ wild mapping populations currently exist for sunflower. Alternatively, many subtle (trichome density or morphology) and biochemical phenotypes have not been measured and thus could not have co-localized with population differentiation. Marker density has become the main limitation in genome scan studies of local adaptation in natural populations [61]. The advent of high-throughput methods such as restriction site associated DNA sequencing (RAD-seq) and genotyping by sequencing (GBS) have allowed researchers to obtain both large numbers of markers and an even genomic distribution [62-64].

\section{Conclusions}

In this study we used 246 loci to characterize the rangewide genetic diversity and structure of the wild progenitor of an economically important crop species. These markers clearly indicated a genetic disjunction between northern and southern populations that occurs around the $40^{\circ}$ north latitude, with populations in Nebraska appearing to be admixed (Fig. 2). This study also generated multiple candidate genomic regions for local adaptation as defined by the extent of their population genetic differentiation. The extent to which these genomic intervals are associated with previous trait mapping experiments is also considered. These loci represent larger physical genomic intervals that will be the focus of future molecular evolutionary analyses, gene expression comparisons across the range, and field studies to further examine their putative role in local adaptation.

\section{Additional files}

Additional file 1: Results of REML analysis of phenotype data. (XLSX $30 \mathrm{~kb}$ )
Additional file 2: STRUCTURE bar plot of southern regions. (PDF $51 \mathrm{~kb}$ ) Additional file 3: Delta $K$ plot for southern STRUCTURE plot found in Additional file 2. (PDF $22 \mathrm{~kb}$ )

Additional file 4: STRUCTURE bar plot corresponding to $K=6$ for the six populations within the southern two regions. (PDF $60 \mathrm{~kb}$ )

Additional file 5: STRUCTURE bar plot of northern regions. (PDF $34 \mathrm{~kb}$ )

Additional file 6: Delta K plot for northern STRUCTURE plot found in Additional file 5. (PDF $10 \mathrm{~kb}$ )

\section{Abbreviations}

AMOVA: Analysis of molecular variance; $G \times E$ : Genotype by environment; GBS: Genotyping by Sequencing; $H_{\mathrm{O}}$ : Observed heterozygosity; LD: Linkage disequilibrium; LG: Linkage group; NMR: Nuclear magnetic resonance; QTL: Quantitative trait locus; RAD-seq: Restriction site associated DNA sequencing; SNP: Single nucleotide polymorphism; $\mathrm{uH}_{\mathrm{e}}$ : Unbiased expected heterozygosity

\section{Acknowledgements}

We thank Scott Jackson's laboratory in the Institute of Plant Breeding Genetics and Genomics at the University of Georgia for greenhouse space and access to lab equipment, and Ben Blackman for providing HaFT sequences for probe design. We thank members of the Burke lab for comments on an earlier version of this manuscript. Special thanks to Caitlin Ishibashi and Jeff Roeder for assisting with the DNA extractions and to Shannon Ritter, Michael Cherry, and Shreyas Vangala for assistance in phenotyping.

\section{Availability of data and material}

The phenotypic analyses are included in the electronic supplementary material associated with this article. The genotyping data has been deposited on Dryad digital repository (http://dx.doi.org/10.5061/dryad.6p1c4).

\section{Authors' contributions}

EVM and JMB conceived the study. EVM performed the common garden phenotyping, SNP genotyping, and population genetic analyses. JC designed SNP chip probes and assisted in genotyping. EVM and JMB drafted the manuscript with input from JC. All authors read and approved the final manuscript

\section{Competing interests}

The authors declare that they have no competing interests.

\section{Funding}

This research was supported by grants from the NSF Plant Genome Research Program (DBI-0820451 and DBI-1444522).

\section{Consent for publication}

Not applicable.

Ethics approval and consent to participate

Not applicable. All seeds were obtained from collections made by the USDA

\section{Author details}

${ }^{1}$ Department of Plant Biology, University of Georgia, Miller Plant Sciences Building, Athens, GA 30602, USA. 'University of Georgia, Center for Applied Genetic Technologies, 111 Riverbend Road, Athens, GA 30602, USA.

${ }^{3}$ Université de Lyon, F-69000, Lyon; Université Lyon 1; CNRS, UMR5558,

Laboratoire de Biométrie et Biologie Evolutive, F-69622 Villeurbanne, France.

Received: 29 June 2016 Accepted: 28 October 2016

Published online: 10 November 2016

References

1. Kawecki TJ, Ebert D. Conceptual issues in local adaptation. Ecol Lett. 2004; 7(12):1225-41.

2. Sambatti JB, Rice KJ. Local adaptation, patterns of selection, and gene flow in the Californian serpentine sunflower (Helianthus exilis). Evolution. 2006; 60(4):696-710. 
3. Turner TL, von Wettberg EJ, Nuzhdin SV. Genomic analysis of differentiation between soil types reveals candidate genes for local adaptation in Arabidopsis lyrata. PLoS One. 2008;3(9):e3183.

4. Turner TL, Bourne EC, Von Wettberg EJ, Hu TT, Nuzhdin SV. Population resequencing reveals local adaptation of Arabidopsis lyrata to serpentine soils. Nat Genet. 2010;42(3):260-3.

5. Knight CA, Vogel H, Kroymann J, Shumate A, Witsenboer $H$, Mitchell-Olds T. Expression profiling and local adaptation of Boechera holboellii populations for water use efficiency across a naturally occurring water stress gradient. Mol Ecol. 2006;15(5):1229-37.

6. Riihimaki M, Savolainen O. Environmental and genetic effects on flowering differences between northern and southern populations of Arabidopsis lyrata (Brassicaceae). Am J Bot. 2004;91(7):1036-45.

7. Arnone JA, Korner C. Temperature adaptation and acclimation potential of leaf dark respiration in two species of Ranunculus from warm and cold habitats. Arctic Alpine Res. 1997;29(1):122-5.

8. Sork VL, Stowe KA, Hochwender C. Evidence for local adaptation in closely adjacent subpopulations of northern red oak (Quercus rubra $\mathrm{L}$ ) expressed as resistance to leaf herbivores. Am Nat. 1993;142(6):928-36.

9. Johnson NC, Wilson GWT, Bowker MA, Wilson JA, Miller RM. Resource limitation is a driver of local adaptation in mycorrhizal symbioses. P Natl Acad Sci USA. 2010;107(5):2093-8.

10. Mercer $\mathrm{KL}$, Wyse $\mathrm{DL}$, Shaw RG. Effects of competition on the fitness of wild and crop-wild hybrid sunflower from a diversity of wild populations and crop lines. Evolution. 2006;60(10):2044-55.

11. Lewontin RC, Krakauer J. Distribution of gene frequency as a test of theory of selective neutrality of polymorphisms. Genetics. 1973;74(1):175-95.

12. Beaumont MA, Nichols RA. Evaluating loci for use in the genetic analysis of population structure. P Roy Soc B-Biol Sci. 1996;263(1377):1619-26.

13. Excoffier $L$, Lischer HE. Arlequin suite ver 3.5: a new series of programs to perform population genetics analyses under Linux and Windows. Mol Ecol Resour. 2010;10(3):564-7.

14. Foll M, Gaggiotti O. A genome-scan method to identify selected loci appropriate for both dominant and codominant markers: A bayesian perspective. Genetics. 2008;180(2):977-93.

15. Polley SD, Chokejindachai W, Conway DJ. Allele frequency-based analyses robustly map sequence sites under balancing selection in a malaria vaccine candidate antigen. Genetics. 2003;165(2):555-61.

16. Cagliani R, Fumagalli M, Riva S, Pozzoli U, Comi GP, Menozzi G, Bresolin N, Sironi M. The signature of long-standing balancing selection at the human defensin beta-1 promoter. Genome Biol. 2008;9:R143.

17. Prunier J, Laroche J, Beaulieu J, Bousquet J. Scanning the genome for gene SNPs related to climate adaptation and estimating selection at the molecular level in boreal black spruce. Mol Ecol. 2011;20(8):1702-16.

18. Nielsen EE, Hemmer-Hansen J, Poulsen NA, Loeschcke V, Moen T, Johansen T, Mittelholzer C, Taranger GL, Ogden R, Carvalho GR. Genomic signatures of local directional selection in a high gene flow marine organism; the Atlantic cod (Gadus morhua). BMC Evol Biol. 2009;9.

19. Bollmer JL, Ruder EA, Johnson JA, Eimes JA, Dunn PO. Drift and selection influence geographic variation at immune loci of prairie-chickens. Mol Ecol. 2011;20(22):4695-706.

20. Richter-Boix A, Quintela M, Segelbacher G, Laurila A. Genetic analysis of differentiation among breeding ponds reveals a candidate gene for local adaptation in Rana arvalis. Mol Ecol. 2011;20(8):1582-600.

21. Coop G, Witonsky D, Di Rienzo A, Pritchard JK. Using environmental correlations to identify loci underlying local adaptation. Genetics. 2010; 185(4):1411-23.

22. Kooyers NJ, Olsen KM. Rapid evolution of an adaptive cyanogenesis cline in introduced North American white clover (Trifolium repens L.). Mol Ecol. 2012; 21(10):2455-68.

23. Stinchcombe JR, Weinig C, Ungerer M, Olsen KM, Mays C, Halldorsdottir SS, Purugganan MD, Schmitt J. A latitudinal cline in flowering time in Arabidopsis thaliana modulated by the flowering time gene FRIGIDA. P Natl Acad Sci USA. 2004;101(13):4712-7.

24. Balasubramanian S, Sureshkumar S, Agrawal M, Michael TP, Wessinger C, Maloof JN, Clark R, Warthmann N, Chory J, Weigel D. The PHYTOCHROME C photoreceptor gene mediates natural variation in flowering and growth responses of Arabidopsis thaliana. Nat Genet. 2006;38(6):711-5.

25. Ingvarsson PK, Garcia MV, Hall D, Luquez V, Jansson S. Clinal variation in phyB2, a candidate gene for day-length-induced growth cessation and bud set, across a latitudinal gradient in European aspen (Populus tremula). Genetics. 2006:172(3):1845-53.

26. Paaby AB, Blacket MJ, Hoffmann AA, Schmidt PS. Identification of a candidate adaptive polymorphism for Drosophila life history by parallel independent clines on two continents. Mol Ecol. 2010;19(4):760-74.

27. Mullen LM, Hoekstra HE. Natural selection along an environmental gradient: a classic cline in mouse pigmentation. Evolution. 2008;62(7):1555-69.

28. Crites GD. Domesticated sunflower in 5th millennium B.P. temporal context - New evidence from Middle Tennessee. Am Antiquity. 1993;58(1):146-8.

29. Harter AV, Gardner KA, Falush D, Lentz DL, Bye RA, Rieseberg LH. Origin of extant domesticated sunflowers in eastern North America. Nature. 2004; 430(6996):201-5

30. Blackman BK, Scascitelli M, Kane NC, Luton HH, Rasmussen DA, Bye RA, Lentz DL, Rieseberg LH. Sunflower domestication alleles support single domestication center in eastern North America. P Natl Acad Sci USA. 2011; 108(34):14360-5.

31. Schneiter AA, American Society of Agronomy., Crop Science Society of America., Soil Science Society of America. Sunflower technology and production. Madison: American Society of Agronomy : Crop Science Society of America : Soil Science Society of America; 1997.

32. Burke JM, Tang S, Knapp SJ, Rieseberg LH. Genetic analysis of sunflower domestication. Genetics. 2002;161(3):1257-67.

33. Box GEP, Cox DR. An analysis of transformations. J Roy Stat Soc B. 1964: 26(2):211-52.

34. Bachlava E, Taylor CA, Tang S, Bowers JE, Mandel JR, Burke JM, Knapp SJ. SNP discovery and development of a high-density genotyping array for sunflower. PLoS One. 2012;7(1):e29814.

35. Nei M. Analysis of gene diversity in subdivided populations. P Natl Acad Sci USA. 1973;70(12):3321-3.

36. Peakall R, Smouse PE. GENALEX 6: genetic analysis in Excel. Population genetic software for teaching and research. Mol Ecol Notes. 2006;6(1):288-95.

37. Pritchard JK, Stephens M, Donnelly P. Inference of population structure using multilocus genotype data. Genetics. 2000;155(2):945-59.

38. Earl DA, Vonholdt BM. STRUCTURE HARVESTER: a website and program for visualizing STRUCTURE output and implementing the Evanno method. Conserv Genet Resour. 2012:4(2):359-61.

39. Evanno G, Regnaut S, Goudet J. Detecting the number of clusters of individuals using the software STRUCTURE: a simulation study. Mol Ecol. 2005;14(8):2611-20.

40. Chen J, Kallman T, Ma XF, Zaina G, Morgante M, Lascoux M. Identifying Genetic Signatures of Natural Selection Using Pooled Population Sequencing in Picea abies. G3 (Bethesda). 2016;10.1534/g3. 116.028753

41. Burke JM, Knapp SJ, Rieseberg LH. Genetic consequences of selection during the evolution of cultivated sunflower. Genetics. 2005;171(4):1933-40.

42. Wills DM, Burke JM. Quantitative trait locus analysis of the early domestication of sunflower. Genetics. 2007:176(4):2589-99.

43. Baack EJ, Sapir Y, Chapman MA, Burke JM, Rieseberg LH. Selection on domestication traits and quantitative trait loci in crop-wild sunflower hybrids. Mol Ecol. 2008;17(2):666-77.

44. Dechaine JM, Burger JC, Chapman MA, Seiler GJ, Brunick R, Knapp SJ, Burke JM. Fitness effects and genetic architecture of plant-herbivore interactions in sunflower crop-wild hybrids. New Phytol. 2009;184(4): 828-41.

45. Linder CR. Adaptive evolution of seed oils in plants: Accounting for the biogeographic distribution of saturated and unsaturated fatty acids in seed oils. Am Nat. 2000;156(4):442-58.

46. Blackman BK, Michaels SD, Rieseberg LH. Connecting the sun to flowering in sunflower adaptation. Mol Ecol. 2011;20(17):3503-12.

47. Blackman BK, Strasburg JL, Raduski AR, Michaels SD, Rieseberg LH. The role of recently derived FT paralogs in sunflower domestication. Curr Biol. 2010; 20(7):629-35

48. Koester RP, Sisco PH, Stuber CW. Identification of quantitative trait loci controlling days to flowering and plant height in two near isogenic lines of maize. Crop Sci. 1993;33:1209-16

49. Bezant J, Laurie D, Pratchett N, Chojecki J, Kearsey M. Marker regression mapping of QTL controlling flowering time and plant height in a spring barely (Hordeum vulgare L.) cross. Heredity. 1996:77:64-73.

50. Kooyers NJ, Greenlee AB, Colicchio JM, Oh M, Blackman BK. Replicate altitudinal clines reveal evolutionary flexibility underlies adaptation to drought stress in annual Mimulus guttatus. New Phytol. 2015;206:152-65. 
51. Mandel JR, Dechaine JM, Marek LF, Burke JM. Genetic diversity and population structure in cultivated sunflower and a comparison to its wild progenitor, Helianthus annuus L. Theor Appl Genet. 2011;123(5):693-704.

52. McMillan C. The role of ecotypic variation in the distribution of the central grassland of North America. Ecol Monogr. 1959;29(4):285-308.

53. Turck F, Fornara F, Coupland G. Regulation and identity of florigen: FLOWERING LOCUS T moves center stage. Annu Rev Plant Biol. 2008;59:573-94.

54. Liu A, Burke JM. Patterns of nucleotide diversity in wild and cultivated sunflower. Genetics. 2006;173(1):321-30.

55. Mandel JR, Nambeesan S, Bowers JE, Marek LF, Ebert D, Rieseberg LH, Knapp SJ, Burke JM. Association mapping and the genomic consequences of selection in sunflower. Plos Genet. 2013;9(3):e1003378.

56. Marks MD, Wenger JP, Gilding E, Jilk R, Dixon RA. Transcriptome analysis of Arabidopsis wild-type and g/3-sst sim trichomes identifies four additional genes required for trichome development. Mol Plant. 2009;2(4):803-22.

57. Panikashvili D, Shi JX, Schreiber L, Aharoni A. The Arabidopsis DCR encoding a soluble BAHD acyltransferase is required for cutin polyester formation and seed hydration properties. Plant Physiol. 2009;151(4):1773-89.

58. Manetas $Y$. The importance of being hairy: the adverse effects of hair removal on stem photosynthesis of Verbascum speciosum are due to solar UV-B radiation. New Phytol. 2003;158:503-8.

59. Brewer CA, Smith WK, Vogelmann TC. Functional interaction between leaf trichomes, leaf wettability and the optical properties of water droplets. Plant Cell Environ. 1991;14(9):955-62.

60. Levin DA. The role of trichomes in plant defense. Q Rev Biol. 1973;48(1):3-15.

61. Flint-Garcia SA, Thornsberry JM, Buckler ES. Structure of linkage disequilibrium in plants. Annu Rev Plant Biol. 2003;54:357-74.

62. Hohenlohe PA, Bassham S, Etter PD, Stiffler N, Johnson EA, Cresko WA Population genomics of parallel adaptation in threespine stickleback using sequenced RAD tags. Plos Genet. 2010;6(2):e1000862.

63. Davey JW, Hohenlohe PA, Etter PD, Boone JQ, Catchen JM, Blaxter ML. Genome-wide genetic marker discovery and genotyping using nextgeneration sequencing. Nat Rev Genet. 2011;12(7):499-510.

64. Elshire RJ, Glaubitz JC, Sun Q, Poland JA, Kawamoto K, Buckler ES, Mitchell SE. A robust, simple genotyping-by-sequencing (GBS) approach for high diversity species. PLoS One. 2011;6(5):e19379.

65. R Core Team. R. A language and environment for statistical computing. R Foundation for Statistical Computing, Vienna, Austira. 2015. http://www.Rproject.org/

\section{Submit your next manuscript to BioMed Central and we will help you at every step:}

- We accept pre-submission inquiries

- Our selector tool helps you to find the most relevant journal

- We provide round the clock customer support

- Convenient online submission

- Thorough peer review

- Inclusion in PubMed and all major indexing services

- Maximum visibility for your research

Submit your manuscript at www.biomedcentral.com/submit 